\section{GRAPHITE IN NUCLEAR REACTORS}

Nuclear Graphite

Edited by R. E. Nightingale. Pp. xiii +547. (New York and London: Academic Press, Inc., 1962.) 112s. $6 d$.

T

HIS book is intended to serve as a reference work for those concerned with the development and uses of graphite in the nuclear energy industry. It has been written by a team of 21 workers, all but one in the United States, and many of them located at the Hanford Laboratories of the General Electric Co., Richland, Washington, where the editor has been working on nuclear graphite for a number of years. The volume of material now existing in the field of nuclear graphite can best be appreciated from the fact that more than five thousand Government reports and journal publications were located and abstracted by the team preparing this book. As might have been anticipated, however, certain chapters of the book, paricularly those concerned with radiation effects on graphite, are already out of date, since the subjectmatter for this volume was current to January 1961, and a number of significant papers have become available in Britain and the United States since that date. The store of knowledge on the behaviour of graphite under irradiation is increasing rapidly at the present time.

The first chapter, written by Nightingale himself, gives an interesting historical review of graphite as a moderator in nuclear piles, and together with its seventy-three references forms a useful introduction for any newcomer to this field. After several chapters by graphite manufacturing technologists, which cover the production, purification, machining and specification aspects, come two chapters on the structure and physical properties of nuclear graphite. The nomenclature used in describing the structure of carbons has never been standardized, and it is not uncommon to find a given term used in several ways in the graphite literature, but Dr. Nightingale gives here a set of clear definitions of the structural units in polycrystalline graphite, and these are adhered to in succeeding chapters of the book.

Chapters 7-14 are the real core of this work, commencing with an excellent article on the theory of radiation effects in graphite by de Halas. This is followed by a brief description of irradiation techniques and then come a series of chapters dealing with radiation effects on the structure, dimensional stability, physical properties, and mechanical properties of graphite. The section devoted to dimensional changes would have been more useful if it had taken into account the papers published by Simmons and Reynolds working at Harwell. Stored energy and radiation annealing effects are each given a chapter to themselves. The next fifty pages deal with the problems of graphite compatibility with gases, and although a bibliography of 157 references is included, the space devoted to aspects of nuclear chemistry seems dispro. portionately small in comparison with the physics sections, bearing in mind the technological importance of graphite reactivity with coolants in nuclear reactors. The final hundred pages of the book are devoted to nuclear technology, with descriptions of some advanced types of reactor systems all of which incorporate graphite as the moderator, and even a brief introduction to graphite moderator design is included.

The very lengthy chapter on physical properties contains a few errors. For example, it is stated on p. 124 that the single crystal of graphite has an orientation ratio of $5: 1$ with respect to thermal conductivity at room temperature. The actual value might be expected to be well in excess of this figure, having regard to the well-known fact that highly oriented pyrolytie graphite has a valie of 100:1. The text is misleading on p. 124, where it states that the thermal expansion of graphite is not a linear function of temperature. In fact, several workers have shown that this property is substantially linear, in any event, from room temperature up to about $2,000^{\circ} \mathrm{C}$. On p. 147 , the elastic constants $S_{11}$ and $S_{12}$ are each stated to be $1 \cdot 8$, whereas the sum of $S_{11}$ and $S_{12}$ equals 1.8. Also, the thermal expansion behaviour of the polycrystalline aggregate was understood long before 1961, and finally, the bond structure of graphite is better known than is stated here.

It is clear that this book will prove invaluable to all physicists and engineers who are concerned with the development and operation of graphite moderated nuclear reactors. It should also be a useful reference work to many scientists who are interested in carbon and graphite, although not necessarily connected with the nuclear industry. Chemists employed in the development of the graphite moderated reactor system may find this work of less value.

F. ROBERTS

\section{MEASUREMENT TECHNIQUES IN MACROMOLECULAR CHEMISTRY}

\section{Analytical Chemistry of Polymers}

Edited by Gordon M. Kline. Part 2: Analysis of Molecular Structure and Chemical Groups. Pp. xiii +619 . Part 3: Identification Procedures and Chemical Analysis. Pp. xii + 566. (High Polymers: a Series of Monographs on the Chemistry, Physics, and Technology of High Polymeric Substances, Vol. 12, Parts 2 and 3.) (Now York and London: Interscience Publishers, a Division of John Wiley and Sons, Inc., 1962.) Part 2 132s.; Part 3 124s.

THE work edited by Dr. G. M. Kline was planned to bring together information on the analytical methods that have proved to be useful in the testing of commercial monomers and polymers. In Part 1 (Nature, 186,52 ; 1960) methods were described for $(a)$ the assay and determination of pertinent impurities in monomers, (b) the identification and characterization of the composition and physical properties of all the major industrial polymers. Parts 2 and 3 summarize our present knowledge of the measurement techniques for the determination of the structure and composition of macromolecules.

Modern instrumental techniques are stressed, and each chapter in Part 2 presents the basic theory underlying the application of the instrumental method of analysis, together with descriptive information on the equipment and methods of procedure. The methods and techniques described in these separate chapters include methods of determination of molecular weights and size, X-ray diffraction, optical methods, differential thermal analysis, pyrolysis, mass spectrometry, ultra-violet and infra-red spectrometry, fluorescence, chromatography, polarography and nuclear magnetic resonance spectro. scopy. Comprehensive data are provided on the characterization of polymers as determined by the various analytical techniques and the application of this information to analytical problems, polymerization processes, polymer structure and stability.

Identification of polymers by systematic procedures, colour tests and microscopy examination is covered in the first three chapters of Part 3. The two concluding chapters describe important developments in the application of radiochemical and end-group analysis to the elucidation of the composition of macromolecules.

All the chapters in these two parts have been written by staff members of the National Bureau of Standards, Organic and Fibrous Materials Division. The volumes provide a most comprehensive and up-to-date review of developments in modern methods of polymer analysis and will be invaluable reference books to all those engaged in the growing subject of polymer science. Dr. Kline and his collaborators are to be congratulated on the bringing together of this excellent and authoritative series of contributions.
C. E. H. BAwN 